\title{
Heterosexual behaviours among men who sell sex to men in coastal Kenya
}

\author{
Adrian D. Smith ${ }^{a}$, Allan D. Muhaari ${ }^{b}$, Carole Agwandab, \\ Dickens Kowuor $^{\mathbf{b}}$, Elise van der Elst ${ }^{\mathbf{b}}$, Alun Davies ${ }^{\mathbf{b}}$, \\ Susan M. Graham ${ }^{b, c}$, Harold W. Jaffe ${ }^{a}$ and Eduard J. Sanders ${ }^{b, d, e}$
}

\begin{abstract}
Objective: African men who have sex with men often sell sex to men, and MSM who sell sex (MSM-SW) often also have female partners. We compared sexual risk behaviour of MSM-SW who were sexually active with female partners (bisexual MSW) to MSM-SW with only male partners (exclusive MSW).

Design: Descriptive behavioural study

Methods: A novel, validated daily event and partner diary self-completed by 82 MSM who sold sex over a follow-up period of 42 days with weekly review. Cumulative individual counts of sex and condomless sex were compiled by partner characteristics. The incidence of specific partnerships and sex acts were compared within and between bisexual and exclusive MSW.
\end{abstract}

Results: Most (59\%) MSM-SW reported female partners during follow-up. The majority of both male and female partners were cash-paying clients originating locally. Bisexual MSW reported a similar rate of condomless sex with male and female partners, but significantly fewer male partners than exclusive MSW. Bisexual MSW had lower HIV prevalence, were more likely to only report insertive anal sex roles, and reported lower frequencies of condomless receptive anal sex than exclusive MSW.

Conclusion: Bisexually active male sex workers in coastal Kenya create HIV and other sexually transmitted infection transmission pathways to partners and clients in both MSM and heterosexual networks, but differed from exclusive MSW in having lower HIV acquisition and transmission risks. Epidemiological projection methods are liable to overestimate bridging potential of MSM-SW and MSM populations without account for systematic differences in risk within these populations.

Copyright (c) 2015 Wolters Kluwer Health, Inc. All rights reserved.

AIDS 2015, 29 (Suppl 3):S201-S210

Keywords: diary study, Kenya, male sex work, men who have sex with men, MSM sex workers, sexual behaviour

\section{Background}

Reviews of HIV prevalence and incidence studies demonstrate the high HIV burden and unmet need for
HIV care among men who have sex with men (MSM) populations in all sub-Saharan settings where studies have been undertaken [1,2]. Transactional activities are commonly documented by men recruited to MSM

\footnotetext{
${ }^{a}$ Nuffield Department of Population Health, University of Oxford, Oxford, UK, ${ }^{b}$ Kenya Medical Research Institute-Wellcome Trust

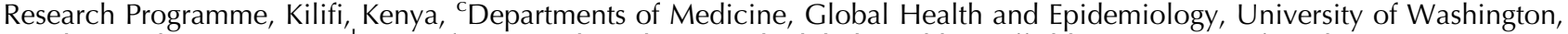
Seattle, Washington, USA, dCentre for Topical Medicine and Global Health, Nuffield Department of Medicine, University of Oxford, Oxford, UK, and ' Department of Global Health, Academic Medical Centre, University of Amsterdam, Amsterdam, the Netherlands.

Correspondence to Adrian D. Smith, Nuffield Department of Population Health, Old Road Campus, University of Oxford, Oxford, UK.

Tel: +44 1865 289239; e-mail: adrian.smith@dph.ox.ac.uk
}

DOI:10.1097/QAD.0000000000000889

ISSN 0269-9370 Copyright (c) 2015 Wolters Kluwer Health, Inc. All rights reserved. This is an open access article distributed under the Creative Commons Attribution License 4.0, which permits unrestricted use, distribution, and reproduction in any medium, provided 
surveys in Africa, and in these surveys MSM reporting recent sex work often have a higher HIV prevalence than MSM who do not [3-9]. MSM sex workers (MSM-SW) - MSM who sell sex to men in exchange for money have received comparatively little specific attention in sub-Saharan Africa [10]. Elsewhere, high HIV acquisition risks among MSM-SW reflect high male partner frequencies and the high biological HIV transmission risk associated with receptive anal sex practices [11-13].

A number of studies of male sex work and HIV risk have been reported from urban settings in Kenya [14-16]. Kenya has a declining generalized HIV epidemic with well characterized concentrated epidemics among key populations, including MSM $[17,18]$. Studies of MSMSW in Nairobi estimate HIV prevalence at $26.3 \%$ (respondent driven sample) [15] and 40.0\% (convenience sample) [14], and a high HIV incidence (10.9 per 100 person-years) [14]. Retrospective behavioural surveys suggest that many MSM-SW report female partners (recall period: 3 month $37.6 \%$ [14], 12 month 49.1\% [15], lifetime $73.6 \%$ [19]), leading researchers and policymakers to speculate about a potential transmission bridging role of MSM-SW between MSM and heterosexual networks $[14,15,20]$.

Mode of transmission models are used across Africa to project the population fraction of new HIV infections attributed to different risk groups using estimates of population sizes, risk behaviour and HIV prevalence, and thereby to assign HIV prevention and control resources effectively [23]. In coastal Kenya, HIV prevalence among MSM is greater than among the general adult population (MSM: 18.2\% [18], women: 6.2\% [22], men: 2.2\% [22]). Mode of transmission studies project that $11 \%$ of all new HIV infections in coastal Kenya arise among MSM (outside prison environments) and, assuming that half of MSM also have female sexual partners, a further $2 \%$ of all new HIV infections occur among female partners of MSM [20]. However, this projection method also implicitly assumes that HIV prevalence and behavioural risk among MSM who have female sexual partners is otherwise no different from MSM who do not.

In this study we describe prospectively ascertained sexual partners and behaviours of MSM-SW drawn from a well established key population cohort study in Coastal Kenya, and compare sexual behaviour of MSM-SW who report female partnerships with those who do not.

\section{Methods}

\section{Study site and population}

The prospective diary study was nested in two ongoing cohort studies of adults at high risk of HIV infection, or with known HIV infection, in Mtwapa, Kenya [21,24]. In brief, these studies recruited adults considered to be at high risk of HIV infection, including MSM, into followup. MSM were identified by a team of $10-15$ peer mobilizers who approached individuals via personal networks and social venues. Follow-up comprised quarterly risk assessment (socio-demographic and behavioural questionnaire), clinical evaluation (symptom history, physical examination) and laboratory assessment [rapid HIV testing, sexually transmitted infection (STI) diagnostics].

All MSM cohort participants who reported sex with another man in the previous 3 months at their most recent risk assessment were invited to participate in the diary study. Diary study volunteers provided written informed consent to participate.

\section{Ethical approval}

Ethical approval for this study was granted by the Kenya Medical Research Institute Ethics Review Board and the Oxford Tropical Research Ethics Committee, University of Oxford.

\section{Diary instrument}

Event diaries were developed in a pilot programme over 6 months with a group of MSM volunteers. The selfcompleted event diary was set in pocket book form for ease of carriage and allowed space for 27 consecutive event entries. Sexual acts with each partner were documented using a pictographic disc (Fig. 1, back translated from Kiswahili). Diary keepers recorded specific sexual acts by drawing a line between body parts of themselves and their partners. Body parts were represented as icons chosen to be meaningful to trained diary users, but not to be interpretable or incriminating if found by someone else. Condom use was indicated by annotation of connecting lines. Characteristics of the sexual partner (e.g. sex, age group, ethnicity, residential origin, and marital status) were recorded by the diary keeper, with an option to indicate if a response was unknown. Recorded characteristics of the dyad included visual coding of cash exchanged for sex and the type of partnership. Regular partners were defined as steady boyfriends, girlfriends and spouses. Casual partners included new partners (defined as partners encountered for the first time) and casual recurrent partners [defined as recurrent partners not considered to be regular partners and back-translated from the Kiswahili mara kwa mara ('from time to time', Fig. 1)].

Participants completed a 4-day training on use of the diary, followed by a 3-week lead-in period during which they were required to demonstrate competence and accuracy in recording. Participants who met this requirement completed a questionnaire at study entry, including data on socio-demographic factors and lifetime sexual behaviour, then were issued with diaries, condoms and lubricants. Thereafter participants completed diaries 

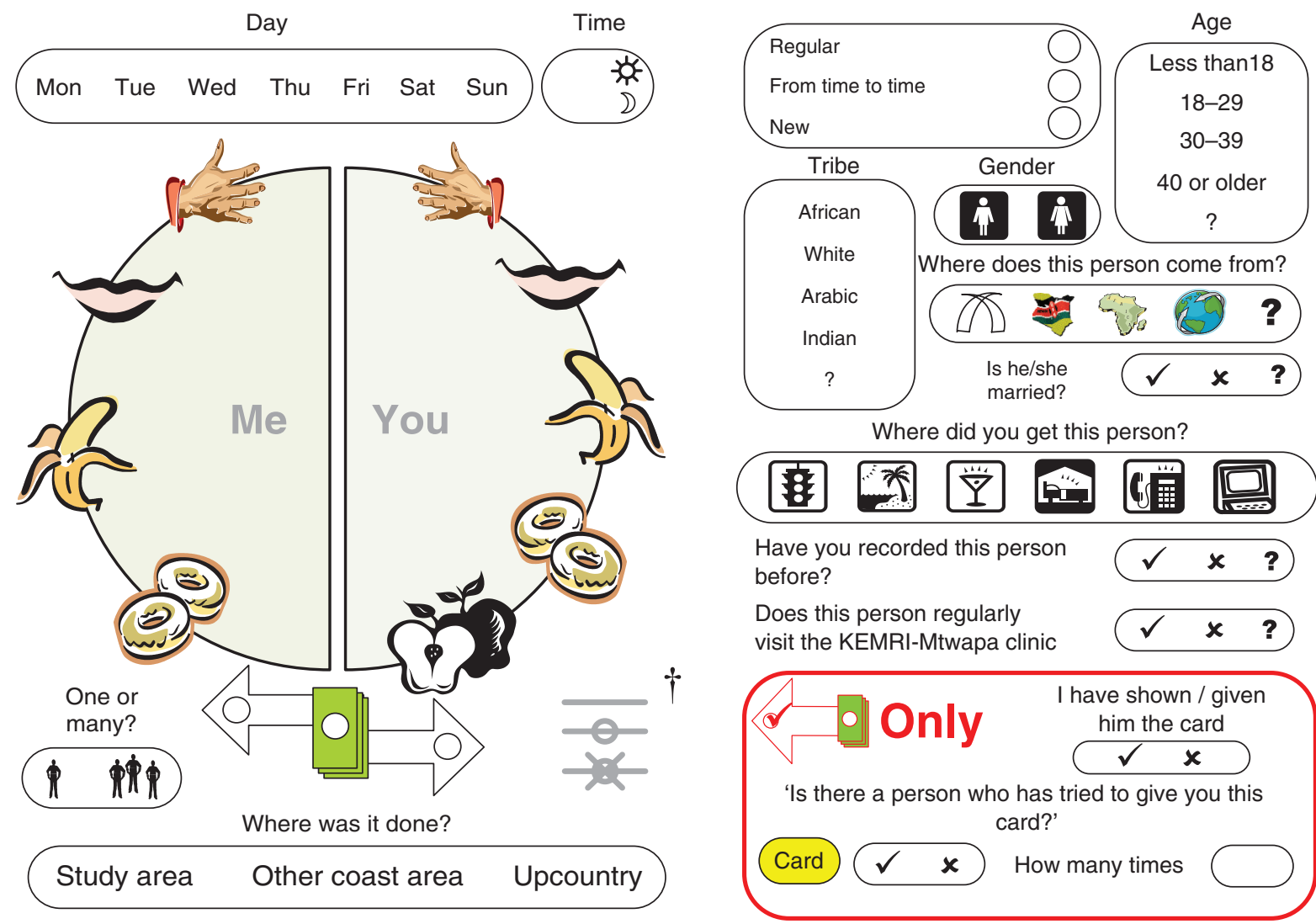

Have you recorded this person before?

Does this person regularly visit the KEMRI-Mtwapa clinic

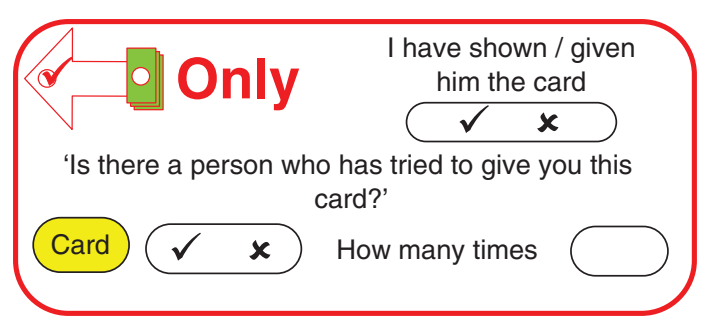

Fig. 1. Event diary instrument (back-translated from Kiswahili). Sexual acts recorded by joining the symbolic body part of the participant (left-hand side of disc, 'me': symbols for hand, mouth, penis (banana), anus (donut) to symbolic body part of partner (right-hand side of disc, 'you' including vagina (apple). Multiple lines indicate repeated rounds of a sexual act. 'Lines appended for condom use and breakage for each round indicated. Partner information (right) included sex, age, ethnicity (tribe), marital status and location of origin [Mombasa (tusks), Kenya, Africa, or international].

for 42 consecutive days each during October-December 2007, depositing completed diaries each week. Event diaries demonstrated high agreement with contemporaneous cohort measures, strong user acceptability in exit evaluation, and high predictive validity against subsequent HIV incidence through January 2011 [25].

\section{Data management and analysis}

Diary entries were error-checked with participants at weekly collection, then double-entered using a pictographic abstraction program (Microsoft FoxPro). Following abstraction, event diaries were archived securely.

Analysis was limited to 82 MSM who reported any sex with a man who paid for sex with cash in the diary study (MSM-SW). One MSM participant did not report selling sex, and was excluded from analysis. We defined behaviourally bisexual MSM-SW (biMSW) as MSMSW who reported sex with male and female partners and behaviourally exclusive MSM-SW (exMSW) as MSMSW who reported only male partners during the diary study. Baseline sociodemographic characteristics of biMSW and exMSW were compared using Fisher's exact test or Wilcoxian rank-sum [26].
Discrete event records were coded to dichotomous variables for each sex act - insertive anal intercourse (IAI), receptive anal intercourse (RAI) and vaginal intercourse, then by condom use for each sex act. Penetrative intercourse was defined as an event in which one or more anal or vaginal acts occurred. Condomless sex was defined as an intercourse event including one or more condom-unprotected acts. The condomless event probability was the fraction of occurrences of a sex act that were condomless. Chi-squared tests were used for direct comparison of proportions $\left(\chi^{2}\right)$.

Event data were compiled into summary counts for each participant, specifically the count of sex acts and condomless sex acts per individual. The incidence of sex acts was described as the average count of sexual acts per 4 weeks of follow-up. Count distributions were strongly positively skewed with best fit to the negative binomial distribution assessed against Poisson, zeroinflated Poisson and zero-inflated negative binomial [27].

To compare sexual behaviour frequency of different participants we used negative binomial regression to estimate the crude incidence rate ratio (IRR) of partner, 
Table 1. Characteristics of study participants who reported selling sex to men during diary follow-up (prospective diary study, Coastal Kenya, 2007).

\begin{tabular}{|c|c|c|c|c|}
\hline & & $\begin{array}{c}\text { BiMSW, } N=48 \\
N(\%) \text { or median IQR }\end{array}$ & $\begin{array}{c}\text { ExMSW, } N=34 \\
N(\%) \text { or median IQR }\end{array}$ & $\begin{array}{l}P \text { value (Fisher's exact } \\
\text { test unless indicated) }\end{array}$ \\
\hline Age & Years & $27(23-32)$ & $25.5(22-30)$ & $0.320^{\mathrm{b}}$ \\
\hline \multirow{3}{*}{ Marital status } & Single & $34(70.8)$ & $30(88.2)$ & 0.084 \\
\hline & Married & $5(10.4)$ & $3(8.8)$ & \\
\hline & Divorced/Widowed & $9(18.8)$ & $1(2.9)$ & \\
\hline \multirow[t]{4}{*}{ Religion } & Catholic & $16(33.3)$ & $10(29.4)$ & 0.841 \\
\hline & Protestant & $14(29.2)$ & $8(23.5)$ & \\
\hline & Muslim & $16(33.3)$ & $14(41.2)$ & \\
\hline & None & $2(4.2)$ & $2(5.9)$ & \\
\hline \multirow[t]{4}{*}{ Highest educational enrolment } & None & & & 0.409 \\
\hline & Primary & $23(47.9)$ & $21(61.8)$ & \\
\hline & Secondary & 19 (39.6) & $11(32.4)$ & \\
\hline & Higher & $6(12.5)$ & $2(5.9)$ & \\
\hline \multirow[t]{3}{*}{ Employment } & Formal employment & $6(12.5)$ & $5(14.7)$ & 0.908 \\
\hline & Self-employment & 19 (39.6) & $14(41.2)$ & \\
\hline & Unemployed & $23(47.9)$ & $15(44.1)$ & \\
\hline \multirow[t]{3}{*}{ Earnings from any source (last month) } & $<2000 \mathrm{KSH}$ & $10(20.8)$ & $11(32.4)$ & 0.417 \\
\hline & $2-5000 \mathrm{KSH}$ & $18(37.5)$ & $13(38.2)$ & \\
\hline & $5000+\mathrm{KSH}$ & $20(41.7)$ & $10(29.4)$ & \\
\hline \multicolumn{5}{|l|}{ Clinical } \\
\hline \multirow[t]{2}{*}{ Circumcised $^{a}$} & Yes & $38(84.4)$ & $29(87.9)$ & 0.751 \\
\hline & No & $7(15.6)$ & $4(12.1)$ & \\
\hline \multirow[t]{2}{*}{ HIV status } & Positive & $4(8.3)$ & $17(50.0)$ & $<0.001$ \\
\hline & Negative & $44(91.7)$ & $17(50.0)$ & \\
\hline
\end{tabular}

biMSW, MSM-SW who reported male and female partners during follow-up; exMSW, MSM-SW who reported only male partners during follow-up; $\mathrm{IQR}$, interquartile range, KSH: Kenyan shilling.

a Data missing for four men.

${ }^{b}$ Wilcoxon rank-sum.

sex act and condomless sex act frequency by participant covariates. Generalized estimating equations (GEE) with a logit link function and exchangeable correlation matrix were used to estimate the odds ratio (OR) of condomless intercourse by participant characteristics, adjusting for correlation of repeated events per participant. Multivariate models were used to estimate independent associations (aIRR and aOR) between participant category and sexual behaviour, adjusted for other participant covariates (HIV status and age). To compare within-individual intercourse and condomless intercourse frequencies, we used GEE with a negative binomial link for panels of paired count measures to estimate the crude within-individual IRR.

\section{Results}

Eighty-two diary participants reported at least one male sexual partner who paid cash for sex over an average follow-up of 41.2 days. At study entry, 65 (79.3\%) MSM-SW reported previous sex with female partners before the study. Forty-eight (58.5\%) MSM-SW reported sex with female partners in event diaries (biMSW) and 34 (41.5\%) MSM-SW reported sex with only men (exMSW).

\section{Participant characteristics}

Table 1 reports selected characteristics of MSM diary study participants who reported selling sex to men during prospective follow-up. Thirty-nine percentage of MSM-SW were under the age of 25. BiMSW were older and more likely to report previous marriage than exMSW, yet were no more likely to presently be married. MSMSW reported low levels of formal employment and income $(2000 \mathrm{KSH} /$ month roughly equivalent to USD $\$ 1 /$ day), yet no differences in participant education, employment, income or religious affiliation were noted between biMSW and exMSW. BiMSW were markedly less likely to be HIV seropositive than exMSW (8.3 and $50.0 \%$ respectively, $P<0.001$ ).

\section{Differences in male-male sexual behaviour between exclusive and bisexual MSW}

MSW diary participants reported 1386 sexual events with men. About $94.4 \%$ events included anal intercourse (Table 2) whilst 5.5\% involved only oral sex or masturbation. On average, biMSW reported 30\% fewer anal intercourse events with male partners than did exMSW (representing four fewer instances of anal sex per 4 weeks per person), a lower rate of condomless anal sex (representing one less instance of condomless sex per 4 weeks per person), but a similar event probability of condomless anal intercourse.

BiMSW reported lower rates of anal intercourse with men than did exMSW in all transaction and relationship categories; however, patterns of male partnership were very similar. BiMSW reported significantly fewer male partners who paid cash for sex than did exMSW (Table 2), but for both groups, paying partners were the vast majority of male sexual contacts (biMSW: $89.1 \%$; exMSW 88.3\%, $\left.\chi^{2} p=0.877\right)$ and condomless male 

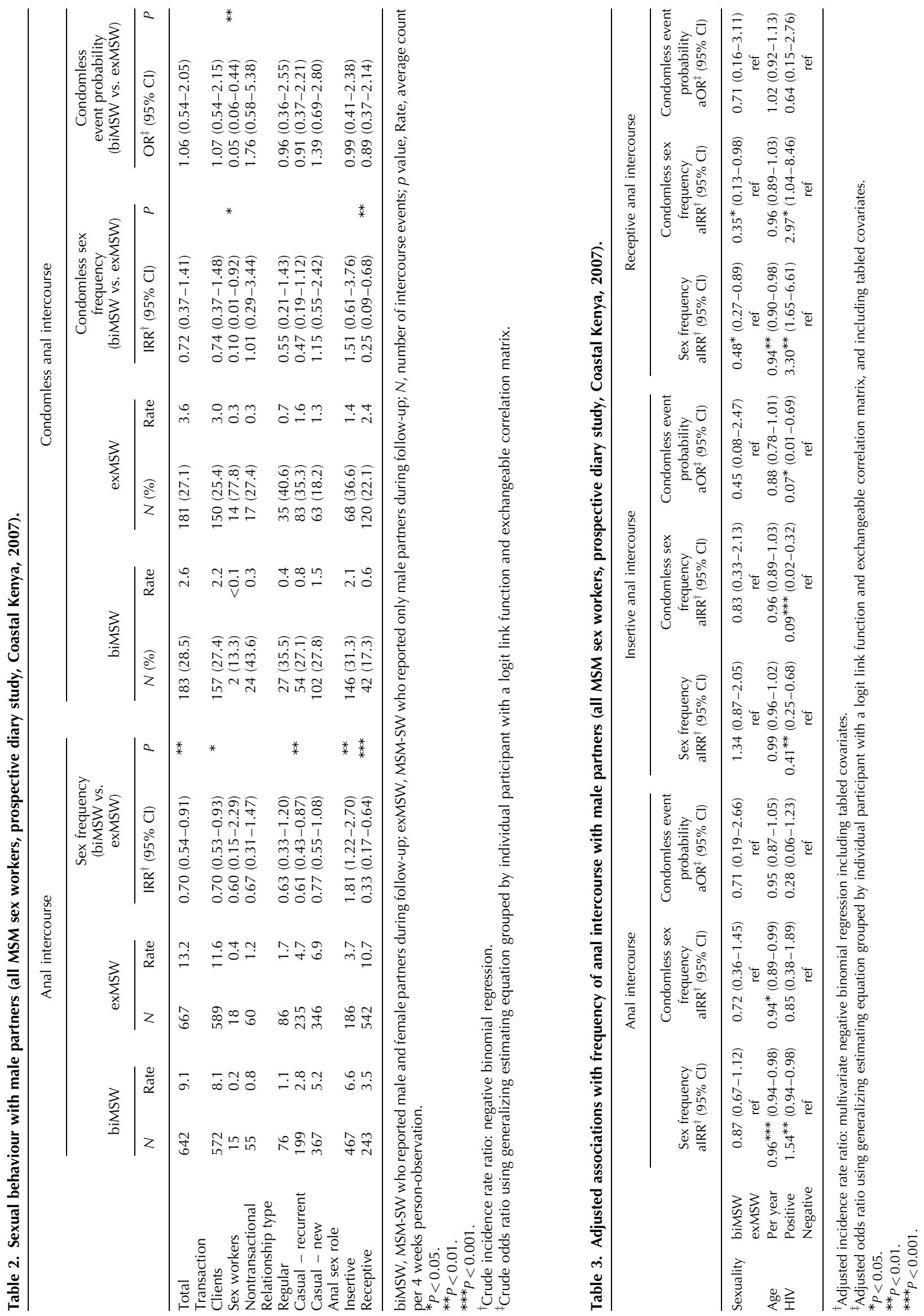
sexual contact (biMSW: 85.8\%; exMSW: 82.9\%, $\left.\chi^{2} p=0.877\right)$. Anal sex acts with men who paid cash for sex were less often condomless than sex with nontransactional male partners [biMSW OR: 0.52, 95\% confidence interval (CI) $0.23-1.19, P=0.124$; exMSW OR $0.52,95 \%$ CI $0.22-1.22, P=0.133$, neither statistically significant]. Purchase of sex from other men was infrequently reported by biMSW or exMSW.

Relationship patterns differed somewhat for biMSW and exMSW. Bisexual MSW reported lower rates of anal intercourse and condomless anal intercourse with repeat male partners (regular or casual recurrent), but a similar rate of anal intercourse and higher rate of condomless anal intercourse with new partners (Table 2). Overall, 55.7\% $(102 / 183)$ of condomless sex with men reported by biMSW was with new partners, whilst most condomless sex reported by exMSW was with recurrent partners $(65.2 \%, 118 / 181)$. There were no significant differences in condomless event probability between biMSW and exMSW by relationship category; however, sex with regular male partners was more likely to be unprotected than sex with casual partners for both biMSW (OR 3.43, 95\% CI 1.32-8.28, $P=0.006$ ) and exMSW (OR 2.93, 95\% CI 1.49-5.77, $P=0.002)$.

Differences in anal intercourse role with male partners were marked. BiMSW reported lower rates of RAI than IAI (within-individual IRR 0.30, 95\% CI 0.19-0.46, $P<0.001)$, whereas exMSW reported the reverse (within-individual IRR 2.23, 95\% CI 1.46-3.43, $P<0.001)$. Compared to exMSW, biMSW were much more likely to 'only' report IAI with men throughout follow-up (biMSW: 50\% vs. exMSW: 11.8\%, Fisher's exact $P<0.001)$.

BiMSW reported significantly lower rates of RAI and condomless RAI than exMSW (Table 2). These associations were independent of the pronounced negative association between increasing participant age and RAI frequency, and strong associations between participant HIV status and RAI and condomless RAI frequency (Table 3). BiMSW did report somewhat higher frequencies of IAI and condomless IAI than exMSW (Table 2); however, there was no independent association after adjustment for the prominent negative associations between IAI frequency, condomless IAI frequency and participant HIV status (Table 3).

Similarly, MSM-SW who recalled sex with females prior to the diary study similarly reported lower prospective frequencies of RAI (aIRR 0.35, 95\% CI 0.16-0.80, $P=0.001$ ) and condomless RAI (aIRR 0.19, 95\% CI $0.06-0.58, P=0.003)$, and higher frequencies of IAI (aIRR 2.65, 95\% CI 1.60-4.37, $P<0.001$ ) and condomless IAI (aIRR 2.08, 95\% CI 0.68-6.40, $P=0.202)$ than MSM-SW who had never previously had sex with a female partner.
Sexual partners and behaviour of bisexual MSW

Bisexually active MSM-SW reported details of 214 female and 510 male partners. Male partners were often in an older age group than participants (male 49.5, female $\left.23.5 \%, \chi^{2} p<0.001\right)$. Most partners were resident in Kenya (male 92.3, female 92.1\%) and of African ethnicity (male 63.9, female 79.3\%). Male partners were more likely to be described as Arabic/Indian than female partners, whereas a minority of both were described as Whites (male 4.3, female 3.3\%). Male partners were more often believed to be married (male: 42.0; female 31.0\%), $\left.\chi^{2} P=0.017\right)$ though this detail was often unknown $(30.4 \%)$.

Table 4 summarizes rates of penetrative intercourse and condomless sex among biMSW with their male and female partners. In addition to intercourse with male partners discussed above, all biMSW reported vaginal intercourse and $79.2 \%$ also reported anal sex with a female partner. In 340 intercourse reports with female partners, $49.1 \%$ were vaginal intercourse only, $10.4 \%$ were anal intercourse only and $40.0 \%$ were both. Condom use did not differ for anal and vaginal intercourse with women (Table 4).

BiMSW reported approximately twice as much penetrative intercourse with men as with women (9.1 vs. 4.8 acts per 4 weeks, IRR 1.83, 95\% CI 1.39-2.40, $P<0.001$, Table 4). This difference consisted of significantly higher intercourse rates with casual and cash-paying male partners. By contrast, more nontransactional intercourse was reported with female rather than male partners, and the vast majority of sex paid for by the participant was with women. A similar proportion of biMSW reported female $(47.9 \%)$ and male $(54.2 \%)$ regular sexual partners (31.2\% reporting both), both accounting for similar intercourse frequencies. With both male and female partners, penetrative intercourse was most likely to be condomless with regular partners or nontransactional partners (Table 4).

Differences in rates of condomless intercourse with male and female partners were more modest than differences in intercourse frequency due to the consistently lower probability of condom use with female partners, compared to male partners (Table 4). As a result, among biMSW, the overall rate of condomless intercourse with female partners was similar to that with male partners $(2.1$ vs. 2.6 condomless acts per 4 weeks, Table 3 ) and $44.5 \%$ $(147 / 300)$ of all biMSW condomless acts were with female partners.

\section{Discussion}

Over a brief duration of detailed prospective observation the majority of MSM who sold sex to men also reported 


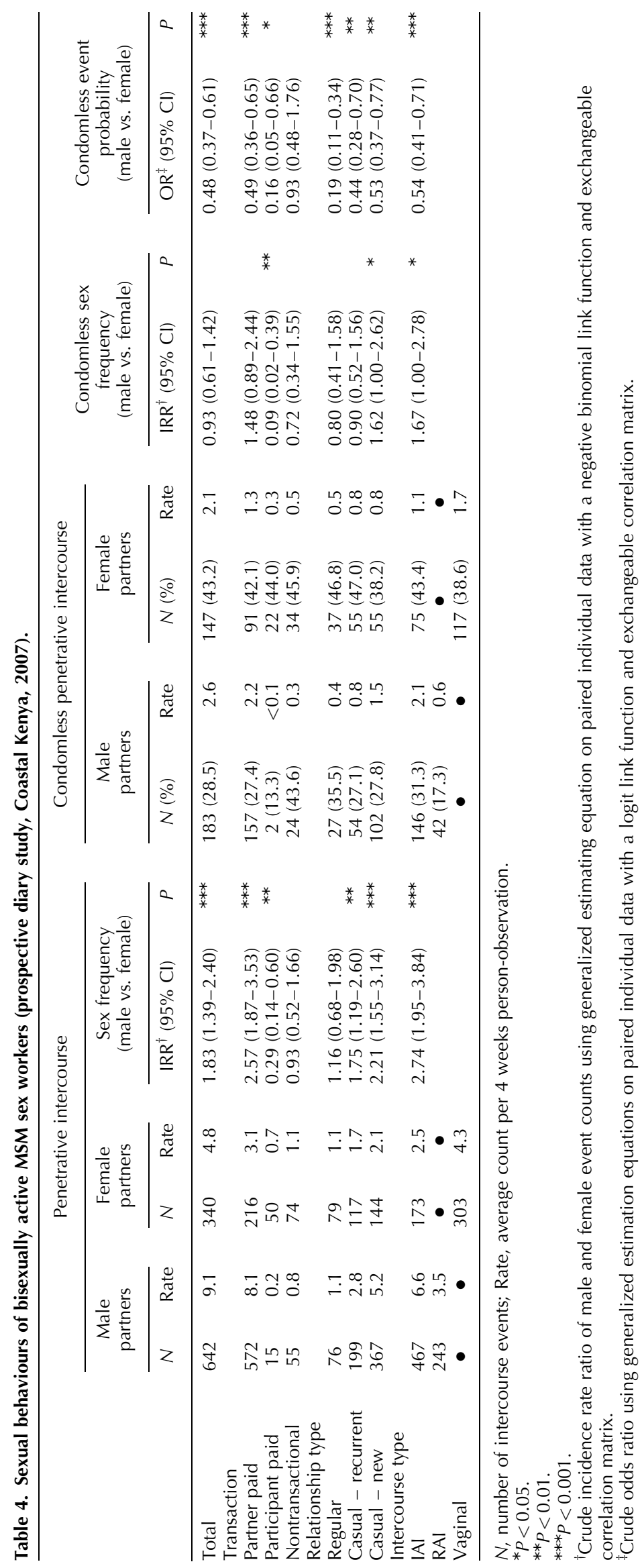


sexual behaviours with women, often including anal intercourse. Sexual activity with both men and women was overwhelmingly characterized as transactional. The existence of female clients who pay for sex from male sex workers on the Kenya coast has previously been indicated by cross-sectional studies of male sex workers on the Kenya coast $[16,19]$, and one study suggests female sex workers commonly report paying for sex with men [28]. Analysis of our findings demonstrates that demand from women represents a significant fraction of male sex work activity, originates mostly from local women and that sex is frequently condomless. These findings both challenge the prevailing characterization of such demand coming from international tourists [29], and highlights the need to investigate a very poorly understood aspect of sexual culture of potential significance to HIV and STI control in Kenya.

Bisexually active MSM-SW reported higher frequencies of sex with male than female partners, but intercourse events with men were much more likely to be condomprotected than those with women. Consequently, overall rates of condomless sex with male and female partners were similar. This suggests ample potential routes of sexual transmission risk of HIV (or other STIs) between biMSW and partners of either sex. From a sexual network perspective, that most MSM-SW report active sexual behavioural links within both MSM and heterosexual sexual networks infers the potential for this group to act as a bridging population between those networks.

These data, however, also suggest that male sex workers who interact with both MSM and heterosexual networks have considerably lower behavioural HIV acquisition risk than those who interact exclusively within MSM networks. HIV prevalence among bisexually active MSM sex workers was markedly lower than among exclusive MSM sex workers, although still higher than estimated prevalence in the local adult male population [22]. These findings concur with a lower HIV incidence reported among bisexually active MSM in the cohort study from which diary study participants were recruited [21]. Similarly, pooled findings of wider sub-Saharan African MSM data suggest that both bisexually identifying and behaviourally bisexual MSM have approximately half the HIV prevalence of other MSM [30].

The above study suggests that heterogeneity in HIV prevalence between biMSW and exMSW reflects heterogeneity in same-sex risk behaviour. BiMSW had fewer male partners, were more likely to take only the insertive role with male partners, and had a significantly lower incidence of RAI and condomless RAI than did exMSW - all indicative of lower HIV acquisition risk. Further, that biMSW were less likely to report anal sex role versatility between partners, and had fewer recurrent male partners, may also suggest that biMSW may be less influential than exMSW upon dynamics of HIV transmission within MSM networks [31]. This study could not directly assess whether either higher RAI frequency or lower heterosexual activity among HIVpositive MSM-SW was in part reactive to knowledge of HIV status. However, whereas seroadaptation may well explain the lower condomless IAI rate and event probability among HIV-positive MSM-SW [32], significant negative associations between RAI and heterosexual activity were consistent across analyses restricted to HIV negative MSM-SW (data not shown), and for both prospective and lifetime measures of sex with female partners suggesting that reverse causation is an insufficient explanation for our findings.

Systematic differences in MSM HIV prevalence and acquisition risks by level of heterosexual activity may be a plausible explanation to resolve the lack of objective phylogenetic evidence of actual HIV transmission bridging across MSM and heterosexual networks to date in Kenya $[33,34]$ with existing projections of significant bridging from models that fail to account for such heterogeneity [20]. However, to what extent patterns of risk behaviour among MSM-SW are generalizable to wider MSM populations in Kenya is uncertain. Local and regional data suggest similar disparities in risk behaviour may well exist in more broadly defined MSM populations. In coastal Kenya, qualitative studies describe Kiswahili MSM identities along very similar behavioural distinctions: basha describing a masculine MSM who takes the insertive sex role, has female partners and passes as heterosexual in wider society, and shoga that evokes notions of femininity, the receptive sex role and which is often appropriated as a term of abuse [35,36]. Few quantitative MSM behavioural studies elsewhere in subSaharan Africa and the diaspora report comparable data, but those that do suggest the same differentiation of anal sex role by heterosexual activity and sexual identity $[11,37,38]$.

The study had a number of limitations. We measured only the direct sexual behaviours and contacts of MSM-SW. That many male and female partners of participants were thought to be married highlights the need for extended network data to comprehensively quantify bridging pathways. It is questionable whether such studies are feasible - our efforts to engage partners and clients of MSM-SW for research confirm that, as elsewhere [39], such groups are exceptionally elusive.

We elected to categorize MSM-SW by behaviour rather than sexual identity, having found low acceptance amongst participants of international terminology categorizing sexuality in preparatory focus groups. Behavioural categorization has the advantage of being objective and unambiguous in directly describing sexual risk, but behaviour may not correspond to personally held notions of sexuality, particularly in the context of sex 
work [40]. Ongoing local qualitative work concurs with observations elsewhere that bisexually active and identifying MSM are less likely to disclose same sex behaviour or access health services $[1,41,42]$, highlighting the need to understand the relationship between behavioural risk and sexual identity in aligning sexual health responses to potentially very diverse notions of individual need and accessibility.

Although the accuracy of prospective event-level measurement in assessing HIV acquisition and transmission risk is well established $[43,44]$, the intensity of follow-up and staff time required was considerable, limiting achievable sample size and the duration of follow-up. Further, findings may not be generalizable to MSM sex workers in other contexts. The study recruited from a research-engaged population of MSM, aware of their HIV status and with free access to relevant information, counselling and prevention materials. Entitlement to services that are otherwise expensive to access is likely to have preferentially selected for recruitment of MSM-SW on low incomes through street-based sex work, which may be unrepresentative of the full spectrum of MSM-SW working locally. 'Highclass' MSM-SW and male escorts on high incomes are known to exist on the Kenya coast, are thought to prefer to seek care from discreet MSM-friendly private services rather than though research clinics, and may exert greater control over sexual risk in transactional interactions. Lastly, inferences are necessarily limited to men who sell sex to men - in light of findings, male sex workers with exclusively female partners and clients may well exist locally, but were not identified or included in this study.

\section{Conclusion}

Bisexually active male sex workers in coastal Kenya create potential transmission pathways for HIV and other sexually transmitted infections to partners and clients in both MSM and heterosexual networks. However, these men are not simply MSM sex workers who happen to have female partners; rather, their behaviour differs from that of exclusive MSM sex workers in important ways that result in a lower risk of HIV infection and transmission. Modelling projections will tend to overestimate the bridging potential of MSM sex workers and other MSM populations unless they account for such risk differences.

\section{Acknowledgements}

The study was part funded by grants from the Department of Public Health, University of Oxford, and the John Fell Fund, OUP, University of Oxford. S.M.G. was funded by National Institute of Mental Health grant R34MH099946. In Kilifi, Kenya, this work was supported by the Kenya Medical Research Institute (KEMRI), the International AIDS Vaccine Initiative and
UW Center for AIDS Research, a National Institutes of Health (NIH) funded programme [P30 AI027757], which is supported by the following NIH Institutes and Centres (NIAID, NCI, NIMH, NIDA, NICHD, NHLBI, NCCAM). The KWTRP at the Centre for Geographical Medicine Research-Kilifi is supported by core funding from the Wellcome Trust (\#077092). This study is made possible by the generous support of the American people through the United States Agency for International Development (USAID). S.M.G. was supported by 5R34MH099946. The contents are the responsibility of the study authors and do not necessarily reflect the views of USAID, the NIH, or the United States Government. This article is published with the permission of the Director of the Kenya Medical Research Institute.

Contribution of authors: A.S., H.J., E.S. conceived the study. A.S. designed the visual diary, A.S., A.M., C.A., A.D., E.vd.E., E.S. conducted participant training, and ran weekly diary exchanges. D.K. developed abstraction database and managed data protocols. A.S. conducted statistical analyses. A.S. wrote the first draft, all authors contributed to the manuscript.

\section{Conflicts of interest}

There were no conflicts of interest.

\section{References}

1. Beyrer C, Baral SD, van Griensven F, Goodreau SM, Chariyalertsak $S$, Wirtz AL, et al. Global epidemiology of HIV infection in men who have sex with men. Lancet $2012 ; \mathbf{3 8 0}: 367-377$.

2. Smith AD, Tapsoba P, Peshu N, Sanders EJ, Jaffe HW. Men who have sex with men and HIV/AIDS in sub-Saharan Africa. Lancet 2009; 374:416-422.

3. Baral S, Beyrer C, Burrell E, Bekker L. Bisexual practices and bisexual concurrency among men who have sex with men (MSM) in peri-urban Cape Town, South Africa. 5th IAS Conference on HIV Pathogenesis, Treatment and Prevention. Cape Town; 2009

4. Baral S, Trapence G, Motimedi F, Umar E, lipinge S, Dausab F, et al. HIV prevalence, risks for HIV infection, and human rights among men who have sex with men (MSM) in Malawi, Namibia, and Botswana. PLoS One 2009; 4:e4997.

5. Burrell E, Mark D, Baral S, Beyrer C, Grant R, Wood R, et al. Comparison of sexual risk behaviors and HIV prevalence between urban and peri-urban men who have sex with men (MSM) in Cape Town, South Africa. MSM preconference to the 2008 International AIDS Conference, Mexico City. Mexico; 2008

6. Dahoma M, Johnston L, Holman A, Miller LA, Mussa M, Othman $A$, et al. HIV and related risk behavior among men who have sex with men in Zanzibar, Tanzania: results of a behavioral surveillance survey. AIDS Behav 2011; 15:186-192.

7. Sanders EJ, Graham SM, Okuku HS, van der Elst EM, Muhaari A Davies A, et al. HIV-1 infection in high risk men who have sex with men in Mombasa, Kenya. AIDS 2007; 21:2513-2520.

8. Wade AS, Kane CT, Diallo PA, Diop AK, Gueye K, Mboup S, et al. HIV infection and sexually transmitted infections among men who have sex with men in Senegal. AIDS 2005; 19:21332140.

9. Nala R, Cummings B, Horth R, Inguane C, Benedetti M, Chissano $M$, et al. Men who have sex with men in Mozambique: identifying a hidden population at high-risk for HIV. AIDS Behav 2015; 19:393-404. 
10. Baral SD, Friedman MR, Geibel S, Rebe K, Bozhinov B, Diouf D, et al. Male sex workers: practices, contexts, and vulnerabilities for HIV acquisition and transmission. Lancet 2015; 385:260 273.

11. Wheeler DP, Lauby IL, Liu KL, Van Sluytman LG, Murrill C. A comparative analysis of sexual risk characteristics of Black men who have sex with men or with men and women. Arch Sex Behav 2008; 37:697-707.

12. Boily MC, Baggaley RF, Wang L, Masse B, White RG, Hayes RJ, et al. Heterosexual risk of HIV-1 infection per sexual act: systematic review and meta-analysis of observational studies. Lancet Infect Dis 2009; 9:118-129.

13. Baggaley RF, White RG, Boily MC. HIV transmission risk through anal intercourse: systematic review, meta-analysis and implications for HIV prevention. Int / Epidemiol 2010; 39:1048-1063.

14. McKinnon LR, Gakii G, Juno JA, Izulla P, Munyao J, Ireri N, et al. High HIV risk in a cohort of male sex workers from Nairobi, Kenya. Sex Transm Infect 2014; 90:237-242.

15. Muraguri N, Tun W, Okal J, Broz D, Raymond HF, Kellogg T, et al. HIV and STI prevalence and risk factors among male sex workers and other men who have sex with men in Nairobi, Kenya. I Acquir Immune Defic Syndr 2015; 68:91-96.

16. Geibel S, Luchters S, King'Ola N, Esu-Williams E, Rinyiru A, Tun $W$. Factors associated with self-reported unprotected anal sex among male sex workers in Mombasa, Kenya. Sex Trans Dis 2008; 35:746-752.

17. Cheluget B, Baltazar G, Orege P, Ibrahim M, Marum LH, Stover J. Evidence for population level declines in adult HIV prevalence in Kenya. Sex Transm Infect 2006; 82 (Suppl 1):i21i26.

18. Kenya National AIDS Control Council. Kenya AIDS Response Progress Report 2014 - progress towards zero. Nairobi, Kenya: NACC. 2014

19. Mannava P, Geibel S, King'ola N, Temmerman M, Luchters S. Male sex workers who sell sex to men also engage in anal intercourse with women: evidence from Mombasa, Kenya. PLoS One 2013; 8:e52547.

20. Kenya National AIDS Control Council. Kenya HIV prevention response and mode of transmission analysis. Nairobi, Kenya: NACC; 2009.

21. Sanders EJ, Okuku HS, Smith AD, Mwangome M, Wahome E, Fegan G, et al. High HIV-1 incidence, correlates of HIV-1 acquisition, and high viral loads following seroconversion among MSM. AIDS 2013; 27:437-446.

22. National AIDS and STI Control Programme. Kenya AIDS indicator survey 2012: final report. Nairobi, Kenya: NASCOP; 2014.

23. Gouws E, Cuchi P. International Collaboration on Estimating HIVIbMoT. Focusing the HIV response through estimating the major modes of HIV transmission: a multicountry analysis. Sex Transm Infect 2012; 88 (Suppl 2):i76-85.

24. Graham SM, Mugo P, Gichuru E, Thiong'o A, Macharia M, Okuku HS, et al. Adherence to antiretroviral therapy and clinical outcomes among young adults reporting high-risk sexual behavior, including men who have sex with men, in coastal Kenya. AIDS Behav 2013; 17:1255-1265.

25. Smith AD. Visual sexual behavioural and partner diaries applied to African MSM. AIDS Vaccine Conference, Bangkok, Thailand; 2011

26. Armitage P, Berry G, Matthews J. Statistical methods in medical research. 4th ed. United Kingdom: Blackwell Science Ltd; 2002.
27. Long JS. Regression models for categorical and limited dependent variables. London: SAGE; 1997.

28. van der Elst EM, Okuku HS, Nakamya P, Muhaari A, Davies A, McClelland RS, et al. Is audio computer-assisted self-interview (ACASI) useful in risk behaviour assessment of female and male sex workers, Mombasa, Kenya? PLoS One 2009; 4:e5340.

29. Kibicho W. Sex tourism in Africa: Kenya's booming industry. Farnham, UK: Ashgate Publishing Limited; 2009.

30. Smith AD. Men who have sex with men and HIV transmission risks in sub-Saharan Africa: a Kenyan case study [DPhil thesis]. Oxford: Oxford University; 2013.

31. Goodreau SM, Golden MR. Biological and demographic causes of high HIV and sexually transmitted disease prevalence in men who have sex with men. Sex Transm Infect 2007; 83:458-462.

32. Cassels S, Katz DA. Seroadaptation among men who have sex with men: emerging research themes. Curr HIV/AIDS Rep 2013; 10:305-313.

33. Tovanabutra S, Sanders EJ, Graham SM, Mwangome M, Peshu $\mathrm{N}, \mathrm{McClelland} \mathrm{RS}$, et al. Evaluation of HIV type 1 strains in men having sex with men and in female sex workers in Mombasa, Kenya. AIDS Res Hum Retroviruses 2010; 26:123-131.

34. Bezemer D, Faria NR, Hassan A, Hamers RL, Mutua G, Anzala $\mathrm{O}$, et al. HIV Type 1 transmission networks among men having sex with men and heterosexuals in Kenya. AIDS Res Hum Retroviruses 2014; 30:118-126.

35. Shepperd G. Rank, gender and homosexuality: Mombasa as a key to understanding sexual options. In: Caplan P. editor. The Cultural Construction of Sexuality London: Tavistock; 1987.

36. Murray S, Roscoe W. Boy-wives and female husbands. Studies of African homosexualities. New York: St. Martin's Press; 1998.

37. Sheehy M, Tun W, Vu L, Adebajo S, Obianwu O, Karlyn A. High levels of bisexual behavior and factors associated with bisexual behavior among men having sex with men (MSM) in Nigeria. AIDS Care 2014; 26:116-122.

38. Lane T, Shade SB, Mclntyre J, Morin SF. Alcohol and sexual risk behavior among men who have sex with men in South African township communities. AIDS Behav 2008; 12 (4 Suppl):S78S85.

39. Carael M, Slaymaker E, Lyerla R, Sarkar S. Clients of sex workers in different regions of the world: hard to count. Sex Transm Infect 2006; 82 (Suppl 3):iii26-iii33.

40. Masvawure TB, Sandfort TGM, Reddy V, Collier KL, Lane T. 'They think that gays have money': gender identity and transactional sex among Black men who have sex with men in four South African townships. Culture Health Sexuality 2015; 17:891-905.

41. $\mathrm{Vu}$ L, Tun $W$, Sheehy $M, \mathrm{Nel} D$. Levels and correlates of internalized homophobia among men who have sex with men in Pretoria, South Africa. AIDS Behav 2012; 16:717-723.

42. Newcomb ME, Mustanski B. Internalized homophobia and internalizing mental health problems: a meta-analytic review. Clin Psychol Rev 2010; 30:1019-1029.

43. Jaccard J, McDonald R, Wan CK, Dittus P, Quinlan S. The accuracy of self-reports of condom use and sexual behavior. J App/ Soc Psychol 2002; 25:1831-1858.

44. Schroder KE, Carey MP, Vanable PA. Methodological challenges in research on sexual risk behavior: II. Accuracy of self-reports. Ann Behav Med 2003; 26:104-123. 